\title{
Peja Tourism Potentials, as Very Important Factors Acknowledged from the World Tourism Organization
}

\author{
Msc. Phd. (c), Merita Begolli Dauti \\ merita_dauti@hotmail.com
}

\author{
Doi:10.5901/ajis.2013.v2n9p686
}

\section{Abstract}

Peja has considerable potentials for developing winter and summer tourism. Worldwide tourism is considered as one of the activities with dynamic development, since in general there is a market for it, with high demands always increasing, being in the same time source of income and employment. Nowadays is one of the strongest industries and as such it has a huge impact in economic and social development of many countries, especially those in development where it is being considered as one of the main income source, employment possibilities, economy diversification, environment protection and promotion of cross cultural exchanges. General characteristic of Peja position is that it lays on the North West part of fertile valley of Dukagjini, in front of the picturesque gorge, under the hills of Albanian Alps. The town is surrendered with mountains, part of the massive, the dynamics that involves whole western Balkan's. These mountains form a crown of peaks such as: Kopranik peak $(2460 \mathrm{~m})$, Zhlep mountain (2352 m), Hajla (2460 m) Mokra (1932m), Lumbardhi mountains, respectively GuriiVerdhë (2522m), Viellaku peak $(2012 \mathrm{~m})$, Peklena, Hasani peak etc. Very convenient geographical position and the relief and climates attributes affected the habitation of these territories since the beginning of indo Europeanization of Balkans peninsula.

Keywords: Tourism, Environment, Potential, Albanian Alps, Mountains

\section{Introduction}

Peja lies on the western part of Republic of Kosovo and it is known as the second city in Kosovo from its territory 0f 603 km2 and it has 130000 habitants. Above sea level of Peja lies between 520 - 550, whereas highest peak is $2522 \mathrm{~m}$ (Pek of Guri I Kuq). Peja lies close to Albanian Alps (Cursed Mountains) and it is on border with Istog, Klina and Decani with municipal, whereas with state borders with Monte Negro and Albania. Reaching Peja city is quite easy having in consideration geographic good position and good road connection with all the cities in Kosovo and with Monte Negro.

The history, culture, tradition, natural wealth, its postion, protected environment, fertile fields, etc, are elements that identify city of Peja as touristic city that it's being visited from different countries visitors. The city has and old history and its being characterised in Kosovo as touristic city.

Except cultural journeys that offers, Peja have a huge natural wealth that sorounds the city in North West part has it is situated only $1 \mathrm{~km}$ from the city centre. The biggest wealth consists of mountain region of Rugova, which is a part of the massive Cursed Mountains. The natural wealths that can be mentioned are: Rugova Gorge, Lumbardhi river, three lakes on the hight of $1860 \mathrm{~m}$, caves, waters, flora and fauna, mountain peaks above $2000 \mathrm{~m}$, etc, that are being offered for visits.

Early development of this city has effected the cultural development and old tradtions, by being passed in time to present. Traditional wearings is one the motiv's that is being saved in original manner and it keeps being used even in present days. Its characterised with black and white colors at male wearing (clothes), whereas the feminine wearings are moustly red.

In peja city and its sorrundings there is a huge number of historic-cultural objects that express the culture and the tradition of this municipality from the time of llyrs until present. There are many historic valuable objects, such as: stone kulla's, old houses, religious objetcs like mosques, catholic and orthodox chuches, hamams, etc.

Municipality of Peja is known as ecologic town with more than $70 \%$ of its territory covered in grrend fields. It's the mountain region of Rugova that makes the biggest part of green fields, with more than $52 \%$ and in the same time its known as the breeze of Peja city. There are attractions, natural and landscape wealths, starting from pitoresque Rugova gorge, Lumbardhi River, three lakes on the hight of $1860 \mathrm{~m}$, caves, waters, diversity of flora and fauna, mountain peaks above $2000 \mathrm{~m}$, etc. Also within the city almost in every corner there are oazes that enrich the city, keep the fresh air and enable the relaxation of the habitants. 


\section{Tourism and touristic offers as promoters of economic development}

Besides other economic sectors, the tourism and agriculture contribution in economic development in Peja municipality it's being considered strategic, consistable and tanglible. Their importance is constantly increased based on the genereal trends and the lack of industry, which before 1999 was the main base for development in Peja. After the renovation, the tourism is ri active and makes a development promotor, facing all kind the challenges by making its mark in touristic zones in Peja municipality. Of course, it keeps importing most of the products and exports huge number of tourists comparing to the expected local and international tourists moustly duruing the summer season and few of them for winter sports .

Although, the number of the visitors its being increased constantly, as well the interst for cultural and natural tourism that provides Peja an competitive advantage. Whereas, the private capital investments (objects, accommodation) and the public investments in road infrastructure, the amount and the quality of services and accommodation are expanding. The role of tourism, independence how small scaled it is in economy, in family incomes and in enployement in Peja municipality is an indicator of success in overall economy.
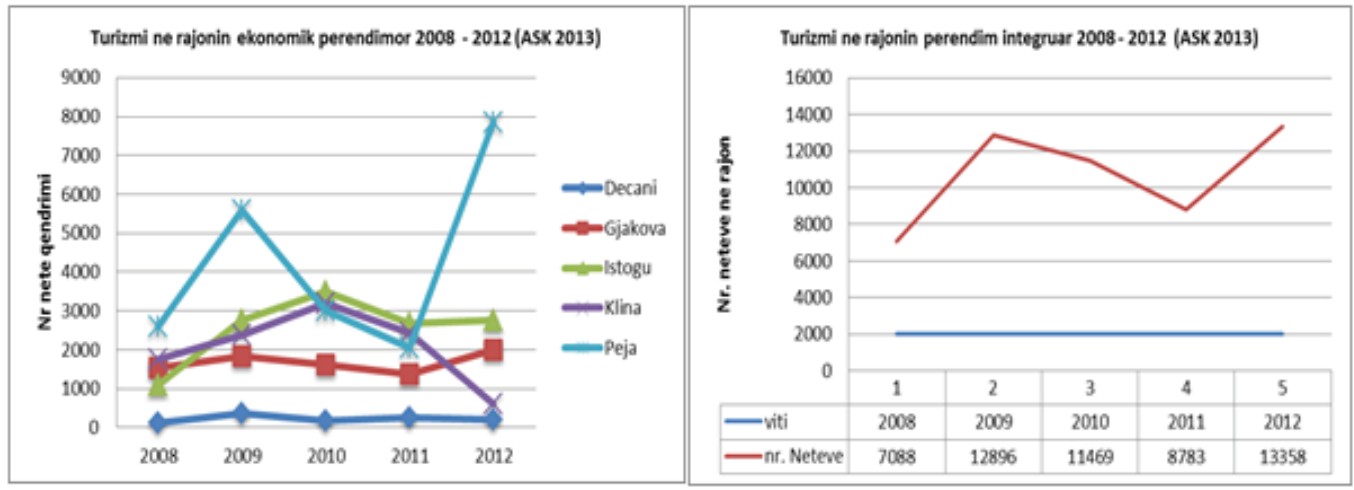

From the data presented, we conclude that the tourism trend measured with overnight stays of local and international tourists in western region (including municipalities of Peja, Decan, Junik, Istog, Klina and Gjakova) is in harmony with the national trends. This means that the number of tourist doubled, with peak increase in 2009, whereas in 2010 and 2011 due to different reasons the percentage decreased, whereas in 2012 the number of tourists was the highest in comparison with last four years.

In individual level, Peja municipality had the highest increase (triple) of the overnight stays in its hotels from local and international toursits in western region, and it is followed from Istog and Gjakova. Decan has a continuous frequence of the overnights, whereas Klina has a decrease from 2010 and onwards

Kosovo, with its cultural and ntural diversity has sufficient potential for tourism development. The zone of border triangle Kosovo- Albania- Monte Negro is continuously becoming more and more attractive from all three governments and Iso from different donors. The zone of border triangle Kosovo- Albania- Monte Negro has an impressive nature and landscapes, a wide biological diversity and it is well known for the warm local hospitality. In the same time, the population of these parts is one of the poorests in the region.

The mountain tourism, such us hiking, biking or mountain climbing in recent years has becomed even more popular. It attracts foreing clients, especialy those from nearby European markets. This consequently creates sustainable incomes for the living population in mountain zones and supports depopulation in this zones. 


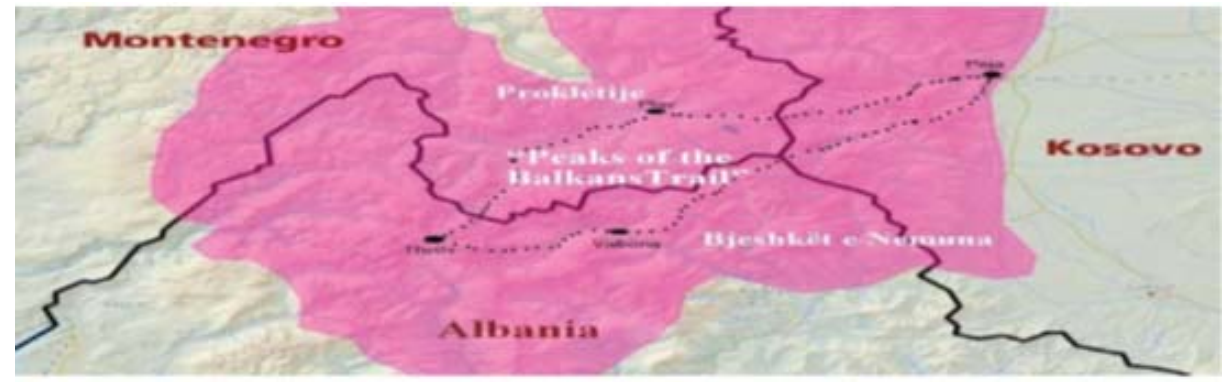

The overall idea it to do marketing to the mountain zones nearby the "Ballkan Peaks" in the zone of border triangle Kosovo- Albania- Monte Negro as the only tourism destination. This way toursits can enjoy the combination of the specialites that each place provides: services gama, diversity of cultural places and beatifull landscapes. This way each destination is more attractive for foreign tourists.

\section{Authentic sheltering forms}

Along the natural beauties and the authentic sheltering forms that represent the regional specifics, they make a cultural attraction for tourists. In the same time they highlight the character of many paths. This causes that these old traditional buildings are often restaurated and offered as guessthouses. Along the traditional way of building, it has the authentic rooms with furnitures selected with a lot of taste (the furniture must not include plastic chairs etc). Often the furnitures are old and localy made out of wood and they give a special impression of the environment only by using small amount of means and lots of creativity.

Some examples from successful trail shelterings in world:

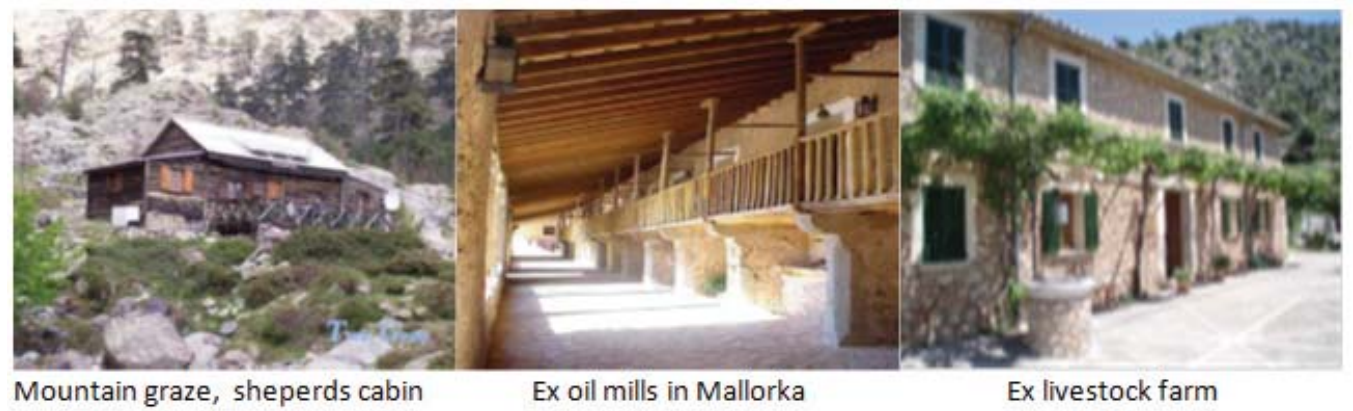

\section{The regional potential}

Sheltering forms in these countries differ that much as the development stage of these three destinations. And this divertisifaction makes these trails so interesting. What is common in three mountain regions ate the old traditional kullas made of stone, which are characteristic for these regions. It is exactly these kullas that needs to be renovated and protected. A success story for added value and use of tradional kullas is the mountain village of Theth.

Except the kullas in Theth there are other sheltering forms available for tourists:

$>$ Wooden houses in Valbona,

$>$ Protecting cabins (Hikingsclubs) and wooden houses in the sourounding mountains in Guisin and Plav,

$>$ Ecolodge in Plav

$>$ Wooden houses, Lodges and restaurants in Peja sourounding mountains 


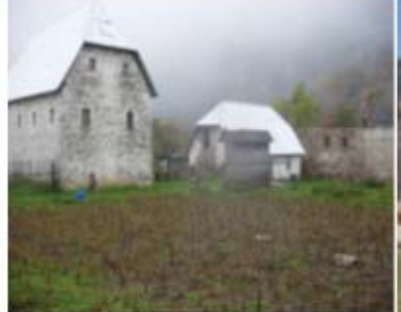

Guesthouse in Theth, Kulla

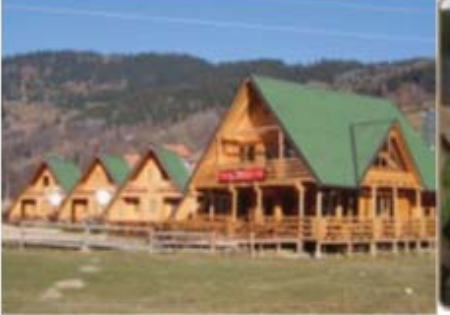

Lodge Rugova Mountains

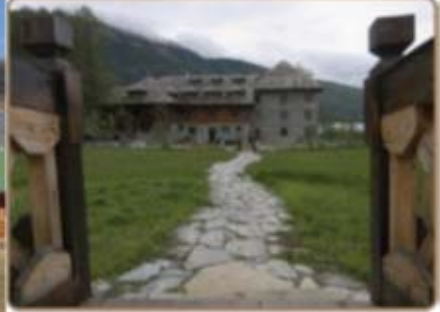

Ecolodge in Plav

\section{Services, service quality and touristc offer}

Service quality: an important indicator for service quality and the additional qualities are the top up's for all touristic products. In general the visitors can enjoy their stay with small effort. Even the small enterprises can ensure a good service. Therefore, the private owners along the base quality services like clean rooms, good breakfast etc, can offer additional services such us fascilitation of guides for the localty or for longer guides, offer travelling maps and distribute informative material for the region. Through a brochure they can attract their attention and share contact information, such us phone numbers etc. Recommendations for simple services must well described in the services guide, already compiled. Additional touristic offer that can be offered for hiking trails can stimulate the interest for the region and bring additional visitors, like for example:

$>$ Mountain guides (professional) that are able to guide in difficult zones and can offer first aid whenever needed. What are completely lacking are the travelling and mountain guides.

$>$ Guides that offer interesting journeys with thematic background (culture, history, flora and fauna).

> In the aspect of Mountain bike tours, guides for mountainbikes, Mountainbikes rental, "Hike \& Bike" is well developmed in Monte Negro and can be taken as an example in other regions.

In winter snow ski, snow tours, (this is very requested from tourists in Rugova Mountains).

Except havin a good road selection and their highlighting a part of the base infrastructure are also the pitoresque views, resting zones and protecting cabins.

These must be placed in certain distance (example every three hours). This can be implemented with very simple means, like for example with materials that can be found on the way, also already existing buildings can be used, like old cabins, food places etc. This principle is being well implemented in Kosovo.

Examples:

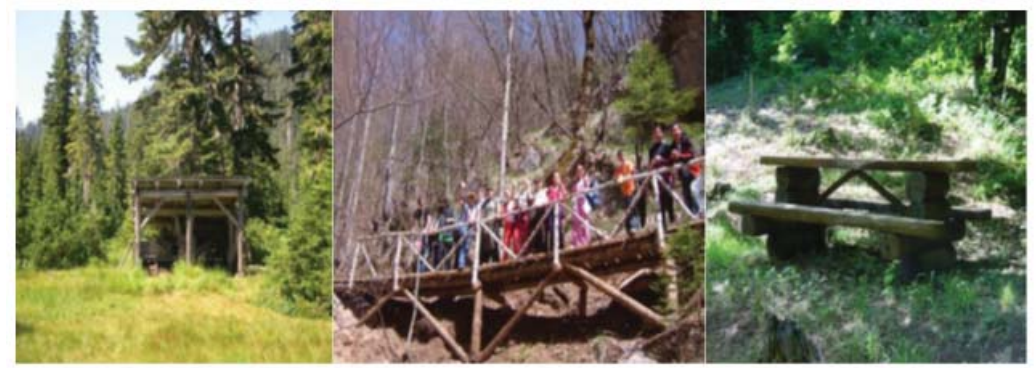

Protective cabins in Kosovo Bridge made of regional materials in Kosovo Picnic seats in Kosovo

\section{Recommendations for further development of sheltering forms in the region}

Active support and reactivation of all kullas in the region.

$>$ Joinly with kulla private owners must be combined with Bed-\&-Breakfast concept, ensuring sufficient sheltering for travellers. Especially in Plav region traditional kullas mus $t$ be reactivated because in comparison with other regions in Plav the tradional buildings are slightly replaced from the modern archiceture. 
$>$ In Theth are already developed base standards for private sheltering that offer breakfast and partly other food also. It would be logical to further develop in a simple standard way regarding quality and services (for example minimal requests for tradional breakfast). And to complie a simple brochure or a quality guide (Visitors beginners book) that can be distributed to the visitors. For the private house owner's practical trainings shpuld be offered. In long term, as for Theth and for the private houses to be build in future it is recommended to offer dubble rooms also except of single rooms in the way not to exclude groups of visitors, such us couples.

$>$ A possible alternative for tradional forms of sheltering is camping. In Theth camping is being practised during the summer season.

There are two main variants:

- Camping with Service: Guest Houses with gardens or ferms with Bed \& Breakfast and sufficient land can offer camping with different services, but for this certain base standards must be placed or at least to be articulated simple recomendationsm, as for example:

$>$ Limited camper number for each guest house,

$>$ Services such us toilet use, breakfast, regional products offer etc,

$>$ Waste collection must be regular.

- No service Camping: for this part of itinerary for which momentaly no shekterings are offered, certain marked zones for camping can be set. Marking is important, in a way that in protecting zones no wild flora is present. It is relevant also te set "Do's \& Dont's": for example taking the waste with you etc. For such free zones for camping moustly are set certain parts of the trails and marked in the map. Increasing the ecological quality (supply and waste collection) in shelter points for example through the use of renewabke nergy (water heating system with solar enery in Theth). Contiuous waste collection and waste water management are a topic for the future and needs improvement.

$>$ Support for the local architecture> to set base recommendations for new buildings Ecolodge type - use of natural materials (wood, stone), local architecture for building elements, authentic style. This must be verified how much this is applied in building in local range. Authentic food, resting possibilities, regional products

$>$ A wide offer with typical regional products, prepared tradinionaly with regional products is another success factor in touristic product "Hiking Trail". Production and distribution of regional products and development of regional trade marks have developed in special fields of economy in some touristic regions.

Theth concept of tradional cousine, with tradional preparation in private houses is implemented completely. Visitors live together with family members and most of the products are produced form the house owners or the neighbours. This is a characterisitic for the village charm and makes an attraction more for the travellers- an example that can be implemented in other shelters along the itinerary. In Kosovo also, in Rugova mountains, in guesthouses are offered tradional food and local treasures.

\section{Recomandations for regional development}

$>$ If the region will be visited and the number of the visitors will increase, that a wider offer in gastronomy must be offered and in resting possibilities.

$>$ Offering and selling of local products, that tourists can buy and take a way. This can be developed in long term (chesnut honey, forest honey, jams etc).

$>$ In all three regions possibilities to rest along the travelin roads lack. In long roads there are neither resting places nor supply- buying places. A good possibility for this would be riactivisation of mountain pastures and opening small shops in where vendor's products could be offered, (fruits, drinks, bread, and cheese).

\section{Conclusion}

Kosovo is well known for potentials for mounitan tourism, national parks, hunting and cultural park. Along the recources the hotelery is concentrated in zones with touristic offers, urban centres and road with high importance in Kosovo. Kosovo has sufficient potentials for development of summer and winter tourism. Tourism is generally considered as one of the activities with dynamic development, since in general for tourism there is a market with high demands always are increasing, concenquently making a income and employment source. Nowdays tourism is one of the massive pheonomens worldwide. Although, the history of tourism development is not old, tourism had a dynamic of fast 
development and included very fast many states and nations worldwide. The importance of tourism for the econmy nowdays is very high. Touristic destinations worldwide are in fact the best indicators from which tourism affects economic activities.

Almost all parts of Kosova have touristic values in different forms and dimensions, independence form recources and development scale. Physiognomy of attraction elements in Kosovo clearly leads you to mountain regions, in the direction of tourstic transtis, big cities, spa's, natural and cultural heritage, hunting localities and villages. Strating from actualities and trends foreseen for the needs of international tourism, real possibilities for lounching a real touristic offer in international market can be excpected in regional centers in Kosova in high mountains, in the direction of theinternational road transit, in the complex of the natural heritage and high cultural values and most important hunting parts. The local touristic requests will further increase for the mountain and village tourism and tourism for the regions with natural and cultural heritage.

\section{References}

Doka .Dhimiter\&Draçi. Bilal:."Gjeografia e Turizmit",Tiranë, 2009.

Gashi. M: "Bazat e Turizmit",Prishtinë,1997

Marinoski.Naume "Bazat e teorisë turistike dhe praktika", Fakulteti turizëm dhe hotelieri, Ohër, 2002.

Ackovski.Nikolla: "Politika mbi zhvilimin e turizmit". Fakulteti për turizëm dhe hotelieri, Ohër, 2005.

Reçica .Fetah.\&Millaku. Bedri:“Ekonomia e Turizmit”, Prishtinë,2011.

Veselaj. Zeqir \& Dr.Morina. Ilir :"Ekologjia",Leksione të autorizuara, Pejë, 2012/13

Agjencia e Statistikës të Kosovës: Statistikat e hotelerisë TM3 - 2012.

Agjencioni për Mbrojtjen e Mjedisit të Kosovës,Prishtinë,2008

Instituti për planifikim hapsinor,Prishtinë,2004.

Ministria e industris dhe tregetisë;Publikime,2001,2007

Ministria e Mjedisit dhe Planifikimit Hapsinor e Kosovës:Publikim,2008.

Zhvillimi i turizmit dhe programi i rregullimit hapësinor të turizmit,Prishtine 2004.

www.giz.de 